Ferrata Storti Foundation

\title{
The TLR7 ligand R848 prevents mouse graft-versus-host disease and cooperates with anti-interleukin-27 antibody for maximal protection and regulatory T-cell upregulation
}

Haematologica 2018

Volume 104(2):392-402

\section{Correspondence: \\ jacques.vansnick@bru.licr.org \\ Received: April 12, 2018. \\ Accepted: September 7, 2018. \\ Pre-published: September 13, 2018.}

doi:10.3324/haematol.2018.195628

Check the online version for the most updated information on this article, online supplements, and information on authorship \& disclosures: www.haematologica.org/content/104/2/392

\section{(C)2019 Ferrata Storti Foundation}

Material published in Haematologica is covered by copyright. All rights are reserved to the Ferrata Storti Foundation. Use of published material is allowed under the following terms and conditions:

https://creativecommons.org/licenses/by-nc/4.0/legalcode. Copies of published material are allowed for personal or internal use. Sharing published material for non-commercial purposes is subject to the following conditions:

https://creativecommons.org/licenses/by-nc/4.0/legalcode, sect. 3. Reproducing and sharing published material for commercial purposes is not allowed without permission in writing from the publisher.
Mélanie Gaignage, ${ }^{1}$ Reece G. Marillier, ${ }^{1}$ Perrine M. Cochez, ${ }^{1}$ Laure Dumoutier, ${ }^{1}$ Catherine Uyttenhove, ${ }^{1,2}$ Jean-Paul Coutelier ${ }^{1}$ and Jacques Van Snick ${ }^{1,2}$

${ }^{1}$ de Duve Institute, Université Catholique de Louvain and ${ }^{2}$ Ludwig Cancer Research, Brussels, Belgium

\section{ABSTRACT}

Tn spite of considerable therapeutic progress, acute graft-versus-host disease still limits allogeneic hematopoietic cell transplantation. We recently reported that mouse infection with nidovirus lactate dehydrogenase elevating virus impairs disease in non-conditioned B6D2F1 recipients of parental B6 spleen cells. As this virus activates TLR7, we tested a pharmacological TLR7 ligand, R848, in this model and observed complete survival if donor and recipients were treated before transplantation. Mixed lymphocyte culture performed $48 \mathrm{~h}$ after R848-treatment of normal mice demonstrated that both T-cell allo-responsiveness and antigen presentation by $\mathrm{CD} 11 \mathrm{~b}^{+}$and $\mathrm{CD} 8 \alpha^{+}$dendritic cells were inhibited. These inhibitions were dependent on IFNAR-1 signaling. In the B6 to B6D2F1 transplantation model, R848 decelerated, but did not abrogate, donor T-cell implantation and activation. However, it decreased interferon-gamma, tumor necrosis factor-alpha and interleukin-27 while upregulating active transforming growth factor-beta 1 plasma levels. In addition, donor and recipient Foxp3 ${ }^{+}$regulatory $\mathrm{T}$-cell numbers were increased in recipient mice and their elimination compromised disease prevention. R848 also strongly improved survival of lethally irradiated BALB/c recipients of B6 hematopoietic cells and this also correlated with an upregulation of CD4 and CD8 Foxp3 ${ }^{+}$regulatory $T$ cells that could be further increased by inhibition of interleukin-27. The combination of anti-interleukin-27p28 monoclonal antibody and R848 showed strong synergy in preventing disease in the B6 to B6D2F1 transplantation model when recipients were sublethally irradiated and this also correlated with upregulation of regulatory $\mathrm{T}$ cells. We conclude that R848 modulates multiple aspects of graft-versus-host disease and offers potential for safe allogeneic bone marrow transplantation that can be further optimized by inhibition of interleukin-27.

\section{Introduction}

Allogeneic hematopoietic cell transplantation (HCT) is an important therapeutic option for a wide range of malignant and non-malignant disorders, including acquired and genetic anomalies. ${ }^{1.3}$ However, it remains plagued by bone marrow failure or graft-versus-host disease (GvHD), which develop in approximately $50 \%$ of allogeneic HCT recipients. ${ }^{4}$ With a death rate in the range of $15 \%,{ }^{5}$ acute $\mathrm{GvHD}$ thus remains a major medical challenge, especially in older patients and in steroid-resistant individuals in whom mortality reaches $90 \%{ }^{6}$

A hallmark of acute GvHD is the release of inflammatory cytokines and a pathogenic contribution has been demonstrated for tumor necrosis factor-alpha (TNF $\alpha){ }^{7}$, interleukin(IL)- $6,{ }^{8} \mathrm{IL}-23^{9}$ and more recently IL-27..$^{10,11}$ This last, a member of the IL-6 and IL12 families, is a cytokine with multiple activities ${ }^{12}$ that both promotes Th1 type immune reactions ${ }^{13}$ and restrains excessive inflammation. ${ }^{14} \mathrm{IL}-27$ is formed by noncovalently linked p28 (also called IL-30) ${ }^{15}$ and Epstein-Barr virus-induced gene 3 product (EBI3), which are structurally related to IL-12p35 and IL-12p40, respectively. ${ }^{13} \mathrm{IL}-27$ 
binds to a heterodimeric receptor, comprising WSX-1/IL$27 \mathrm{R} \alpha$ and gp130. This receptor signals through STAT1 and STAT3 and is expressed on hematopoietic stem cells, all lymphoid and myeloid cells, vascular endothelium and keratinocytes. ${ }^{16} \mathrm{IL}-27$ is produced by macrophages, monocytes and dendritic cells (DC) and its receptor is expressed on memory CD4 and CD8 T cells. ${ }^{13,17,18}$ In the context of GvHD, IL-27 inhibition confers protection by downregulating interferon-gamma (IFN $\gamma$ ) and upregulating Foxp3-expressing regulatory $\mathrm{T}$ cells (Treg) that represent a major control point of GvHD severity, as reported previously. ${ }^{19-21}$

We recently made the surprising observation that lactate dehydrogenase elevating virus (LDV), a single-stranded positive-sense RNA enveloped mouse nidovirus, enhanced survival in the lethal form of acute GvHD induced by B6 spleen cell injection into non-conditioned B6D2F1 recipients. ${ }^{22}$ In this model, which is mainly characterized by severe bone marrow failure ${ }^{23}$ and liver destruction, LDV protection correlated with a transient impairment of antigen presentation by $\mathrm{DC}$ and with alterations in T-cell allo-responsiveness, both dependent on IFNAR-1 signaling, in agreement with the reported GvHD inhibition by type I interferons. ${ }^{24}$

As LDV activates Toll-like receptor 7 (TLR7), ${ }^{25}$ we considered the possibility that the TLR7 agonist resiquimod (R848), ${ }^{26}$ an imidazoquinoline originally developed as an antiviral agent ${ }^{27}$ and an immune adjuvant, ${ }^{28}$ could replicate the protective effects of the virus. This idea is somewhat counterintuitive since $\mathrm{R} 848$ has adjuvant activity and promotes Th1 immune reactions. ${ }^{29}$ However, prolonged exposure of mice to the compound was reported to induce a disruption of the lymphoid system resembling that induced by human immunodeficiency virus. ${ }^{30}$

We here report that a transient treatment of mice with R848 just before allogeneic HCT conferred strong protection against GvHD which correlated with inhibition of inflammatory cytokine production, upregulation of transforming growth factor-beta (TGF- $\beta$ ) and Treg and could be further enhanced by anti-IL-27 monoclonal antibody (antiIL-27) therapy.

\section{Methods}

\section{Mice}

Mice were bred under specific pathogen-free conditions at the animal facility of the Ludwig Cancer Research Brussels Branch under the direction of Guy Warnier (DVM). Experimental protocols and animal handling were approved by the ethical committee of the Medical Faculty of the Universite de Louvain (accreditation n.: 2016/UCL/MD/010). IFN- $\alpha / \beta \mathrm{R}^{-1} 129 / \mathrm{Sv}$ mice (IFNAR-1/) were a gift from Dr. M. Aguet.

\section{Reagents}

Donor and/or recipient mice were injected intraperitoneally 48 $\mathrm{h}$ and $24 \mathrm{~h}$ or $0 \mathrm{~h}$ before donor cell implantation with $25 \mu \mathrm{g} /$ mouse resiquimod (R848) (Cat. ALX-420-038-M005, EnzoLifeSciences, NY, USA). Anti-IL-27p28 monoclonal antibody (aIL-27) (clone: MM27.7B1) is a previously described mouse IgG2a antibody. ${ }^{32}$ Recipient animals were given $0.5 \mathrm{mg}$ intraperitoneally on days 0 and 6 after transplantation. Anti-CD25 antibody (clone: PC61) was generated in-house from hybridomas obtained from the American Type Culture Collection (Manassas, VA, USA). ${ }^{33}$ Donor and recipient mice were treated with two intraperitoneal injections of antiCD25 antibody (400 $\mu \mathrm{g} /$ mouse) 6 days before and 1 day after donor cell transfer.

\section{Other detailed methods}

All other methods are described in the Online Supplementary Methods.

\section{Results}

R848 prevents lethal parent to F1 non-conditioned graftversus-host disease

The effect of R848 was first tested in non-conditioned (nc) GvHD to avoid the inflammatory cytokine burst induced by host irradiation. The agent was administered to recipient B6D2F1 and/or donor B6 mice 24 and 48 h before donor spleen cell injection. Data pooled from five experiments showed $100 \%$ mortality in control mice by day 25 . R848 treatment of either recipient or donor resulted in survival rates of $40 \%$ and $60 \%$, respectively, while combined treatment of both resulted in 100\% long-term survival (Figure 1A). Morbidity evaluated by weight loss was also totally suppressed after donor and recipient treatments (Figure 1B). Timing of R848 administration was important since treatments given too early (6-5 days before transplantation) or too late (5-6 days after transplantation) were not protective (Figure 1C). R848 treatment also minimized hepatocyte destruction but mononuclear cell infiltration was still present (Figure 1D). This tissue protection was confirmed by suppression of serum amyloid $A(S A A) 1 / 2$ and $S A A 3$ mRNA expression in liver cells (Figure 1E).

Finally, after 14 days, host spleen cell numbers had dropped from $\pm 50 \times 10^{6}$ to $\pm 2 \times 10^{6}$ in the control GvHD group but remained unchanged or even slightly increased after R848 treatment, demonstrating host spleen cell protection by R848. Spleen cell implantation by R848-treated B6 donors was low after 14 days, approximately $4 \times 10^{6}$ cells, but increased with time, resulting in a permanent chimerism reaching 20x10 $10^{6} 6$ cells per spleen after 100 days (Figure 1F).

R848 treatment inhibits production of IFN $\gamma$, TNF $\alpha$ and IL-27 but stimulates active TGF- $\beta 1$ secretion in non-conditioned graft-versus-host disease

B6 $\rightarrow$ ncB6D2F1 GvHD was characterized by high concentrations of plasma IFN $\gamma$ and IL-27 that reached maxima at day 10 and returned to nearly undetectable levels by day 14. R848 treatment essentially abolished these cytokine peaks (Figure 2A). RNA analysis confirmed upregulation of Ifng expression in spleen and liver of untreated transplanted mice and its complete silencing by R848 (Figure 2B). A similar inhibition was seen for TNF $\alpha$ (Figure 2A), a cytokine that also contributes to GvHD pathology. ${ }^{34}$ Given the potential implication of TGF- $\beta$ in the control of GvHD, 35,36 we also measured TGF- $\beta 1$ and TGF- $\beta 3$ by enzyme-linked immunosorbent assays selectively detecting the active forms of these cytokines and observed a strong upregulation of the former (Figure 2A), but not the latter (data not shown) after R848 treatment. As shown in Figure 2A, active TGF- $\beta 1$ was upregulated from day 6 to day 14, but was no longer detectable at day 50 (data not shown).

\section{R848 treatment before hematopoietic cell transplantation inhibits T-cell allo-responsiveness and major histocompatibility complex presentation by conventional dendritic cells through type I interferon signaling}

Optimal prevention of $\mathrm{B} 6 \rightarrow \mathrm{ncB} 6 \mathrm{D} 2 \mathrm{~F} 1 \mathrm{GvHD}$ required treatment of both donor and recipient with R848. Since 
A
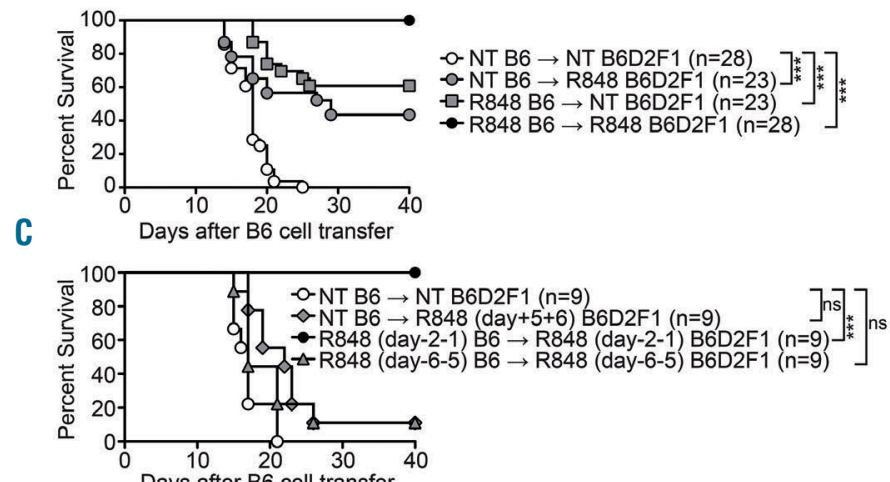

E

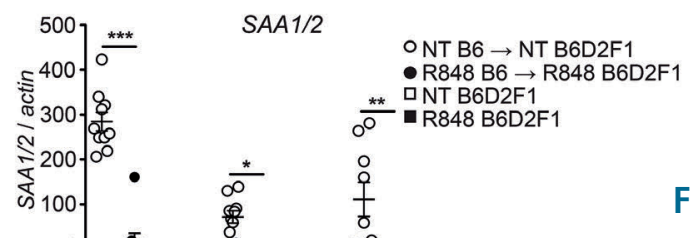

B

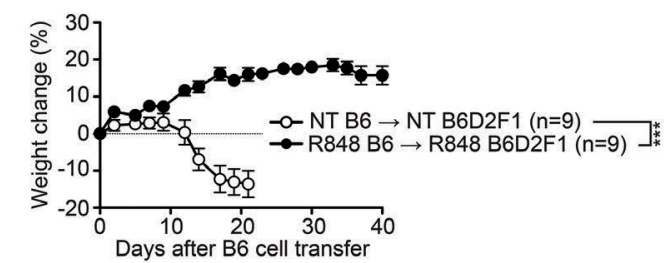

$\mathrm{D} \longrightarrow \mathrm{NT} B 6 \mathrm{D} 2 \mathrm{~F} 1 \quad \mathrm{NT} \mathrm{B6} \rightarrow \mathrm{NT} \mathrm{B} 6 \mathrm{D} 2 \mathrm{~F} 1 \mathrm{R} 848 \mathrm{~B} 6 \rightarrow \mathrm{R} 848 \mathrm{~B} 6 \mathrm{D} 2 \mathrm{~F} 1$
$\mathrm{F}$

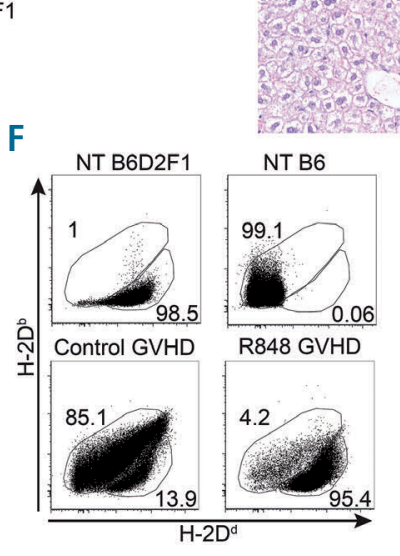

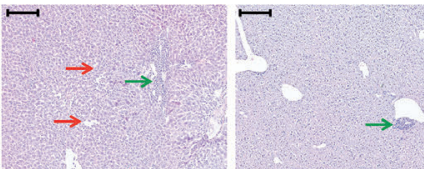
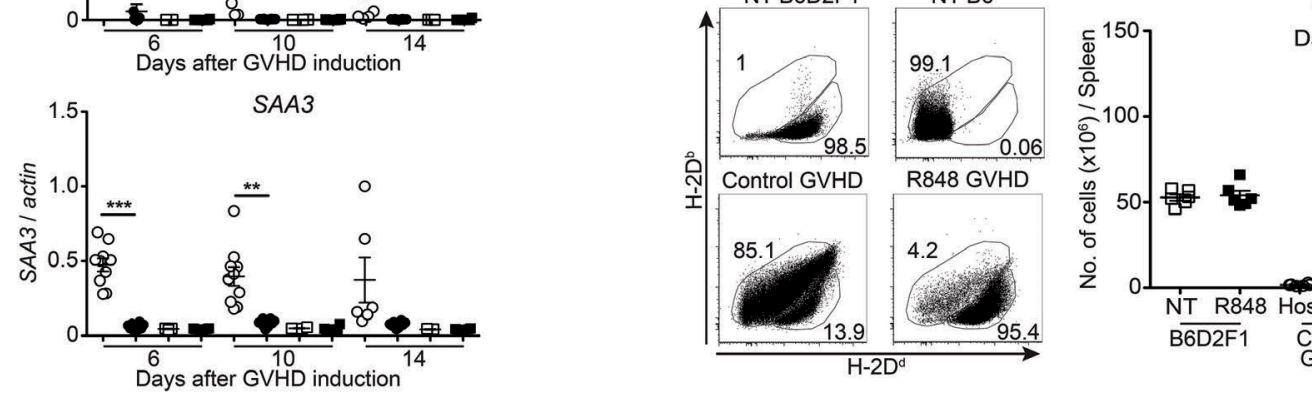

Day 14

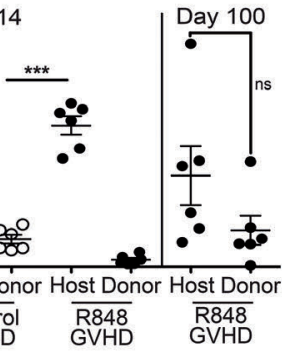

Figure 1. R848 treatment of recipient B6D2F1 and donor B6 mice before spleen cell transfer completely blocks non-conditioned graft-versus-host disease. B6D2F1 mice, treated with R848 or not ( $25 \mu \mathrm{g}$ at 48 and $24 \mathrm{~h}$ before transplantation), were injected intraperitoneally with $60 \times 10^{6}$ spleen cells from B6 mice nontreated (NT) or treated with R848, $48 \mathrm{~h}$ before cell transfer. Mice were monitored for (A) mortality and (B) weight loss. (C) R848 treatment kinetics: B6D2F1 and B6 mice were treated with R848 (25 ug) twice ( 6 and 5 days before; 2 and 1 days before and 5 and 6 days after B6 cells transfer) and recipients were monitored for mortality. (D) Liver sections were prepared from NT B6D2F1, control or R848 14 day-GvHD mice. Hematoxylin \& eosin-stained slides were analyzed for histopathological damage and representative sections illustrate mononuclear inflammatory cells present in portal tracts (green arrow) and large-dilated sinusoidal spaces (red arrow) are indicated. Scale bars in the upper and lower panels represent 200 and $50 \mu \mathrm{m}$, respectively. (E) RNA was extracted from total liver and analyzed by realtime quantitative polymerase chain reaction for SAA1/2 and SAA3 expression. (F) After 14 days of GvHD induction, spleen cells from NT B6 $\rightarrow$ NT B6D2F1 (control)

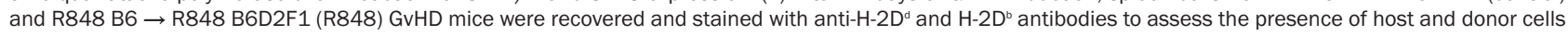
by flow cytometry. On the left, representative mouse dot plots illustrating percentages (gated on total living cells) and on the right, absolute numbers of host ( $\left.\mathrm{H}-2 \mathrm{D}^{\mathrm{b}}\right)$ and donor $\left(\mathrm{H}-2 \mathrm{D}^{\mathrm{d} / \mathrm{b}}\right)$ cells are shown. Overall survivals are depicted $(* * * P<0.001$ by the log-rank test). Data are from three to five experiments ( $P<0.05, * * * P<0.001$ by the Kruskal-Wallis test with Dunn multiple comparison test or ANOVA-Bonferroni post-test).

host $\mathrm{T}$ cells are not reactive against the implanted parental cells, the action of R848 on the F1 partner is likely on antigen presentation. To assess the influence of $\mathrm{R} 848$ on this process and on T-cell responsiveness, normal B6D2F1 and B6 mice were injected with R848 or phosphate-buffered saline for two consecutive days before spleen cell collection. B6 spleen cells were then incubated with B6D2F1 irradiated adherent spleen cells as a source of antigen-presenting cells (APC). In control mice, this combination induced strong proliferation and IFN $\gamma$ production. R848 treatment of either B6D2F1 stimulating or B6 responder mice inhibited proliferation and IFN $\gamma$ production (Figure 3A), indicating that 48 $h$ of treatment with R848 of otherwise non-manipulated mice impaired both antigen presenting and responder cells.

TLR7 activation leads to production of type I interferons. ${ }^{26}$ We, therefore, tested the implication of IFN in R848mediated T-cell suppression in allogeneic mixed lymphocyte cultures using spleen cells from $129 / \mathrm{Sv}\left(\mathrm{H}-2 \mathrm{D}^{6}\right)$ or
129/Sv-IFNAR-1 ${ }^{-/}$mice as responder cells and B6D2F1 irradiated adherent spleen cells as APC. This experiment confirmed the inhibitory effect of R848 on the allogeneic responder cells in a different mouse strain and showed that, in $129 / \mathrm{Sv}$-IFNAR- ${ }^{-/}$responder cells, proliferation and IFN $\gamma$ production were not inhibited (Figure 3B). R848-induced inhibition was not correlated with an increase in Foxp3 ${ }^{+}$ Treg (Figure 3C) and depletion of Treg with anti-CD25 PC61 antibody before R848 treatment did not prevent the inhibition of IFN $\gamma$ production during the allogeneic mixed lymphocyte culture (Figure 3D).

We previously showed that TLR7 viral stimulation transiently inhibits conventional DC (cDC), the only splenic cells able to activate an allogeneic T-cell response in vitro. ${ }^{22}$ To evaluate the effect of R848 on allogeneic antigen presentation in the allogeneic mixed lymphocyte culture, CD11 b+ cDC, $\mathrm{CD} \mathrm{a}^{+} \mathrm{cDC}$ and $\mathrm{pDC}$ were purified from $129 / \mathrm{Sv}$ mice $48 \mathrm{~h}$ after $\mathrm{R} 848$ treatment and co-cultured with FVB (H-2 $\left.{ }^{9}\right)$ 


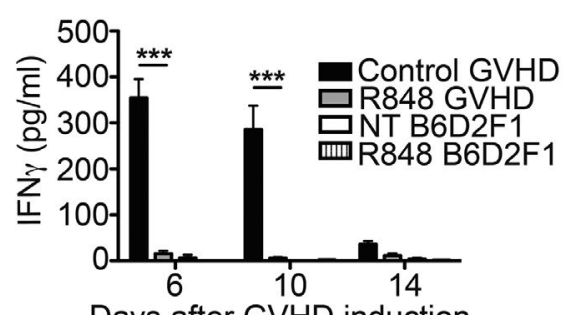

Days after GVHD induction

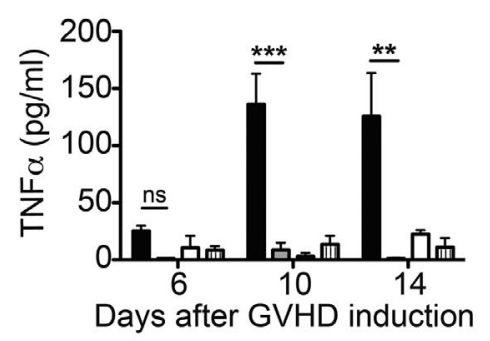

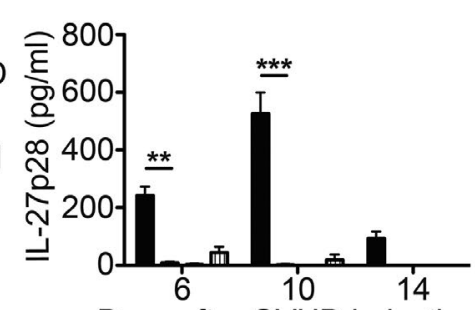

Days after GVHD induction

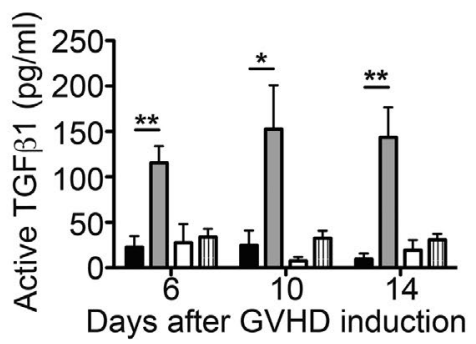

Figure 2. R848 treatment lowers inflammatory cytokines but increases active transforming growth factor beta-1 in nonconditioned graft-versus-host disease. GvHD was induced by the transfer of $60 \times 10^{6} \mathrm{~B} 6$ spleen cells into B6D2F1 recipients. One group was left non-treated (Control GvHD) and in one group, both recipients and donors were treated with R848 48 and $24 \mathrm{~h}$ before transplant ( $R 848$ GvHD). (A) IFN $\gamma$, IL-27p28, active TGF $3-1$ and TNF $\alpha$ were measured in plasma by enzyme-linked immunosorbent assay. (B) Spleen and liver cells were analyzed by real-time quantitative polymerase chain reaction on days 6,10 and 14 . IFNy gene expression, normalized against $\beta$-actin, is shown. RNA was extracted from total spleen and liver. Data are pooled from two independent experiments and representative of three $(* P<0.05, * * P<0.01, * * * P<$ 0.001 by the Kruskal-Wallis test with Dunn multiple comparison test).

B
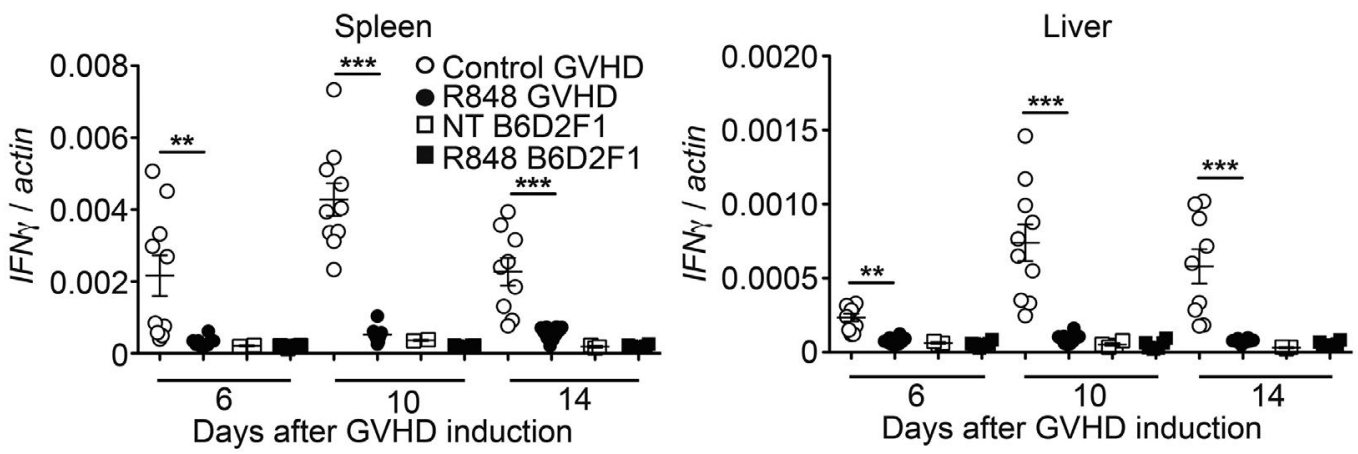

CD4 T cells. CD11b and CD8 $\alpha^{+}$cDC were the main stimulating cells in the mixed lymphocyte culture and this capacity was impaired in mice treated with R848 (Figure 3E). This suppression of APC was also dependent on IFNAR-1 (Figure 3F).

These data indicate that at the time of donor cell transfer, R848 administration inhibited both antigen stimulation by $\mathrm{cDC}$ and $\mathrm{T}$-cell responsiveness in a type 1 interferon-dependent process. This impairment of T-cell allo-responsiveness induced by R848 after $48 \mathrm{~h}$ did not involve Treg.

R848 treatment impairs effector donor T cells and increases regulatory $T$ cells in a non-conditioned graft-versus-host disease model

To evaluate the effect of $\mathrm{R} 848$ on responder $\mathrm{T}$ cells during GvHD, we first used CFSE-labeled CD5 B6 cells. Six days after transplantation, staining dropped considerably in B6 cells transplanted into B6D2F1 but not into B6 recipients. This loss of CFSE staining, although diminished, still occurred in R848-treated mice with GvHD, indicating that donor cell division was not completely suppressed by R848 (Figure 4A). The slower expansion of donor $\mathrm{T}$ cells after R848 treatment was confirmed by the decrease in implanted donor CD4 and CD8 T cells 14 days after transplantation (Figure 4B). However, ultimately R848 did not abrogate B6 donor cell engraftment as chimerism was still detected up to 100 days after transplantation (see Figure 1G). Donor

CD8 T cells were also five times less abundant in R848-protected GvHD than in control ncGvHD. These effects were not the consequence of R848 toxicity for $\mathrm{T}$ cells since host CD4 $\mathrm{T}$ cells remained unchanged (Figure 4B).

The persistence of donor $T$ cells in the R848-protected mice raised the question of the activation state of these cells. We evaluated the proportion of naive and memory cells with CD62L and CD44 labeling, respectively. The massive loss of CD62L expression by CD4 T cells observed in control ncGvHD was partially inhibited by $\mathrm{R} 848$ (67\% in control mice, $3.9 \%$ in control GvHD and $26 \%$ in R848-protected $\mathrm{GvHD}$ ) and the same trend was seen for CD8 T cells, indicating that donor T-cell activation was partially inhibited by R848 (Figure 4C). In contrast, the upregulation of CD44 on CD4 T cells was not significantly modified by R848 (2.50-fold upregulation in control and 2.45 fold with R848, Figure 4C). With regards to the activation marker CD69, its expression was unchanged by R848 on CD8 T cells and even somewhat enhanced on CD4 T cells (Figure 4D). In contrast to B6 donor cells, there was no significant change in CD44/CD62L T-cell proportions in control and R848 recipient groups. However, in control GvHD, as the B6D2F1 splenocytes were destroyed, their numbers dramatically dropped (Online Supplementary Figure S1A) whereas in the R848 group, the numbers of CD44 ${ }^{+}$and $\mathrm{CD} 62 \mathrm{~L}^{+} \mathrm{T}$ cells were significantly more important than in control GvHD but remained in the same order as in naïve mice. In 
A

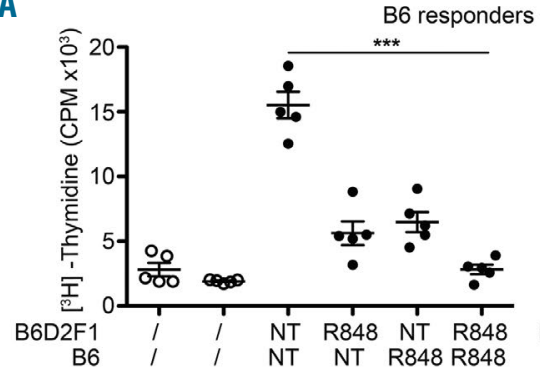

B

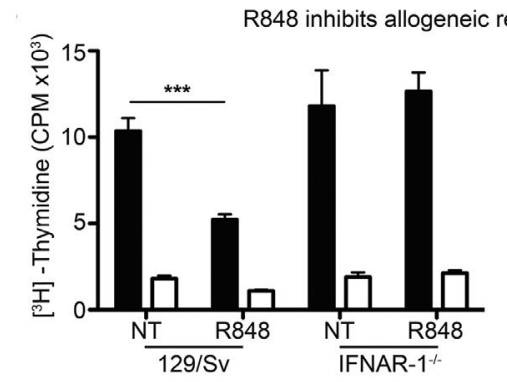

C

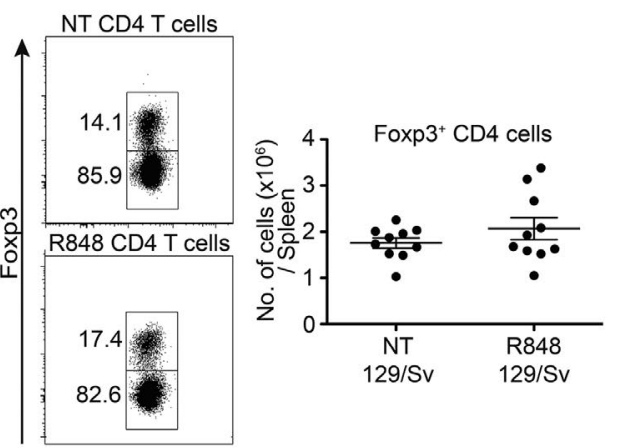

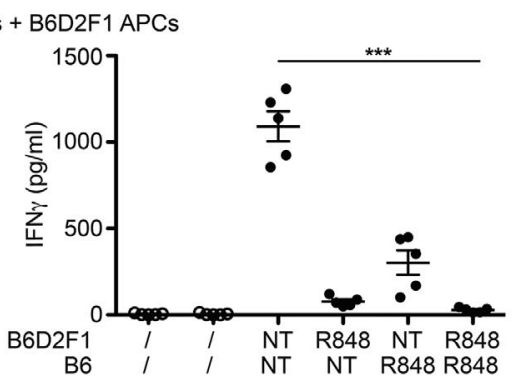

esponder cells through IFNAR-1 signaling

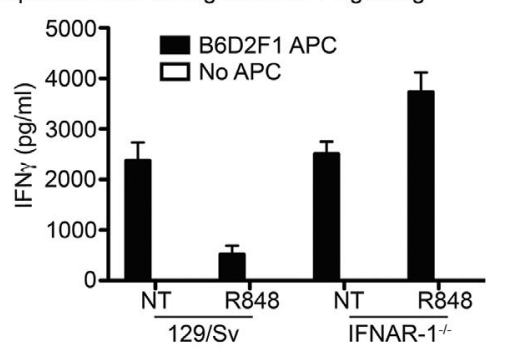

D

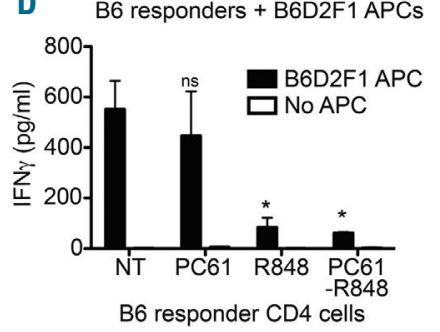

E

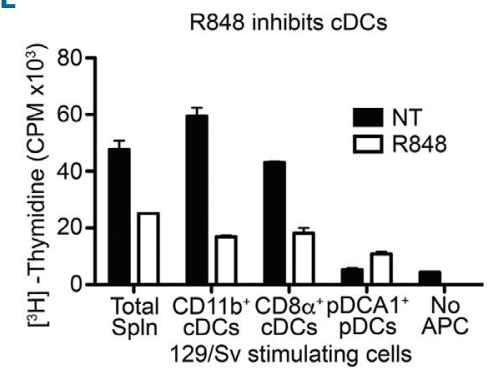

F R848 inhibits allogeneic APCs
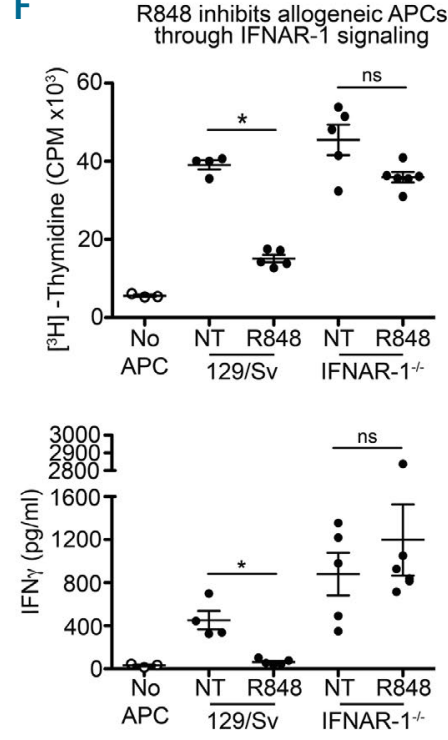

Figure 3. In vivo treatment of mice with R848 affects responder and presenting cells in mixed lymphocyte culture: role of IFNAR-1. (A) B6D2F1 and B6 mice were treated or not with R848 (25 $\mu \mathrm{g}) 48$ and $18 \mathrm{~h}$ before mixed lymphocyte culture of B6 responder cells and irradiated B6D2F1 APC. After $48 \mathrm{~h}$, (left) proliferation and (right) IFN $\gamma$ production were determined by ${ }^{3} \mathrm{H}$-thymidine incorporation and enzyme-linked immunosorbent assay, respectively. (B) Spleen cells from $129 / \mathrm{Sv}$ and $129 /$ Sv IFNAR-1\% mice were collected $48 \mathrm{~h}$ after in vivo R848 treatment and incubated with B6D2F1 APC. Proliferations and IFNy were measured. (C) $129 /$ Sv spleen cells cells were stained for CD4, LIVE/DEAD ${ }^{\oplus}$ and Foxp3 to determine the percentage and absolute numbers of Treg. (D) Treg were depleted with PC61 antibody in B6 mice 4 days before R848 treatment. B6 spleen cells were collected $48 \mathrm{~h}$ after in vivo R848 treatment and incubated with B6D2F1 APC and IFN $\gamma$ was measured after $72 \mathrm{~h}$. (E) FVB $\left(\mathrm{H}^{\mathrm{q}}\right.$ ) splenocytes were incubated without APC or with CD11 $\mathrm{b}^{+} \mathrm{CDC}, \mathrm{CD} 8 \mathrm{a}^{+} \mathrm{cDC}$ or pDC purified by MACS beads and FACS sorting from normal and R848-treated 129/Sv mice. After $48 \mathrm{~h}$, proliferation was recorded. (F) Spleen cells from 129/Sv and 129/Sv IFNAR-1\% mice were collected $48 \mathrm{~h}$ after R848 treatment and co-cultured with FVB responder splenocytes. Proliferation and IFNy were measured. Data are from two to four experiments in all panels (* $P<0.05, * * * P<0.001$ by the Kruskal-Wallis test with Dunn multiple comparison test).

addition, an increase was observed for CD69+ CD4 T cells in R848-protected mice as compared to control B6D2F1 mice (Online Supplementary Figure S1B).

We next examined the influence of R848 treatment on Treg in the same experiments. First, we observed a 10-fold decrease in the proportion of donor and recipient Foxp3 $3^{+}$ CD4 T cells 14 days after B6 spleen cell transplantation. In contrast, in R848-treated GvHD mice, recipient Foxp3 ${ }^{+} \mathrm{CD} 4$ $\mathrm{T}$ cells increased 4-fold while donor Treg returned to normal B6 levels (Figure 4E).

Together, these data indicate that during ncGvHD R848 affected donor CD4 and CD8 T-cell implantation and activation but the inhibition was only partial and did not prevent the establishment of permanent chimerism. On the other hand, R848 prevented GvHD-induced loss of donor and recipient Treg and even increased the latter above normal levels.

\section{Regulatory T cells contribute to R848-mediated} prevention of non-conditioned graft-versus-host disease

The contribution of Treg to the protective effect of R848 was tested by depletion of Treg using anti-CD25 PC61 antibody treatment of B6 donors and B6D2F1 recipients. PC61 antibody was injected 4 days before R848 treatment and a second injection was administered 1 day after B6 spleen cell transplantation. As compared to donor CD4 $\mathrm{T}$ cells from R848-treated mice with GvHD, B6 CD4 T cells from the PC61-R848 GvHD group engrafted host spleen faster and their numbers were significantly higher at 14 and 20 days after B6 cell transfer and continued to expand up to day 50. PC61 antibody completely depleted their Foxp3 ${ }^{+}$Treg population which remained totally absent during the course of GvHD in contrast to that in the R848-treated mice, in which they expanded more than 6-fold from day 14 to day 50 (Figure 5A). Regarding host Treg, in PC61-R848-treated 
A
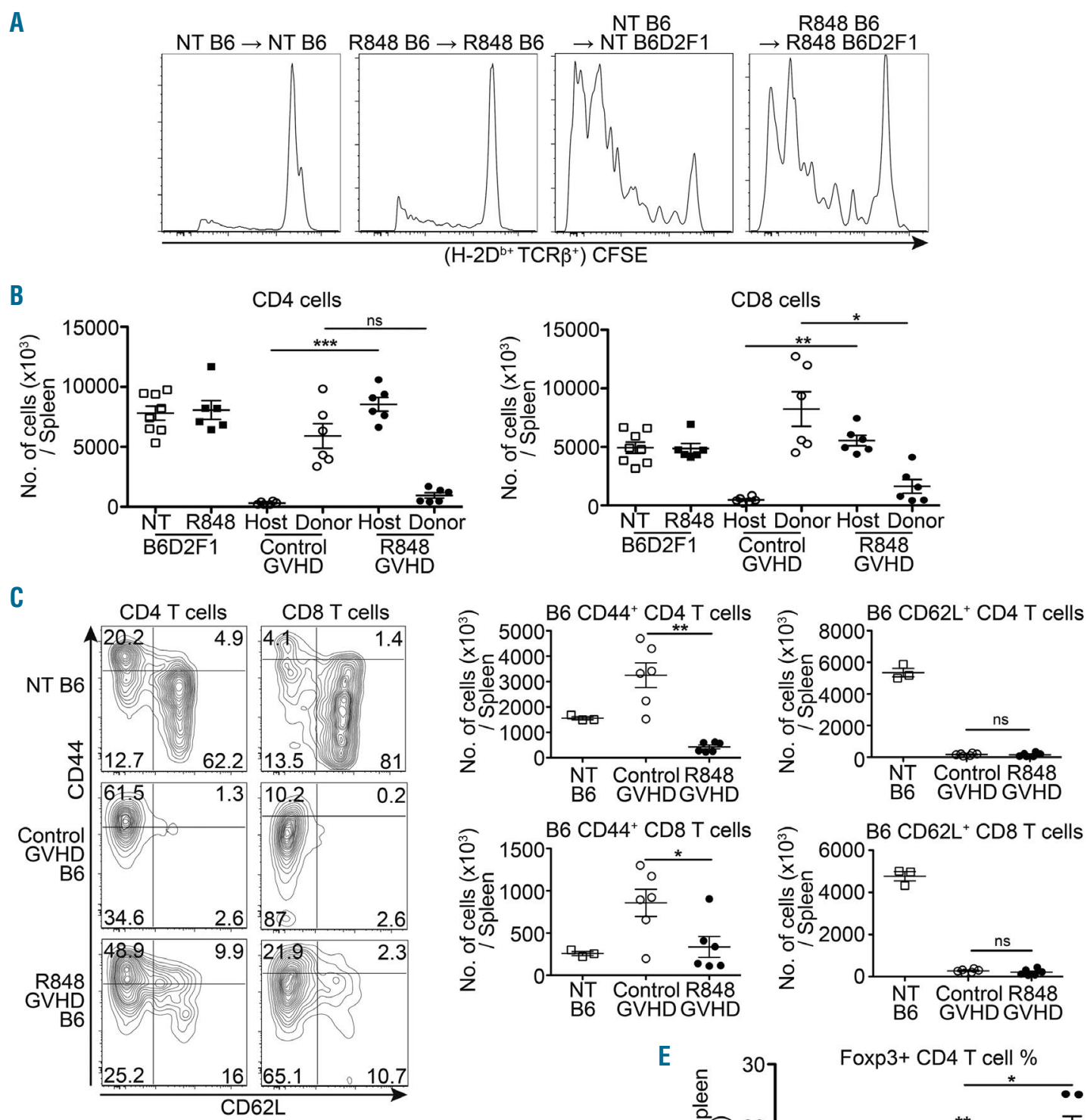

D

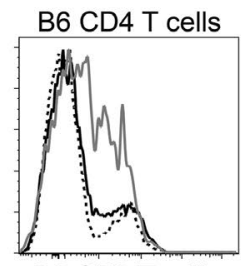

B6 CD8 T cells

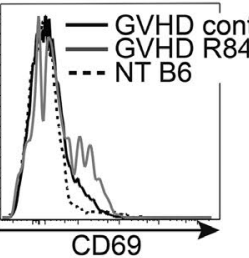

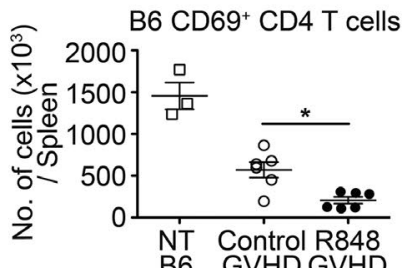

B6 GVHD GVHD

B6 CD69 ${ }^{+} \mathrm{CD} 8 \mathrm{~T}$ cells

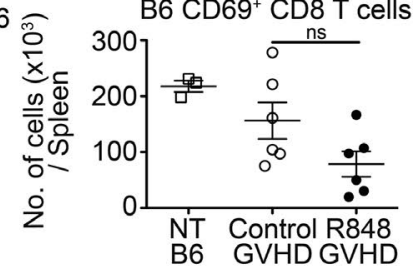

E
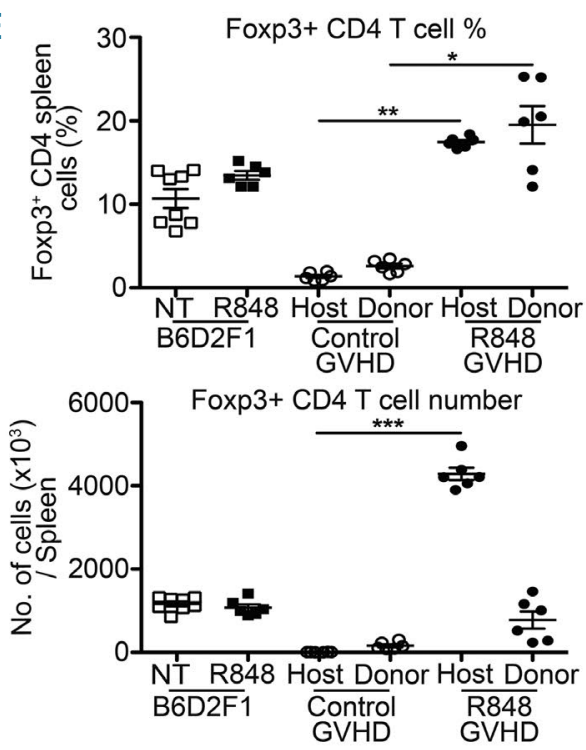

Figure 4. R848 treatment lowers effector T cells but increases regulatory T cells during non-conditioned graft-versus-host disease. (A) B6D2F1 and B6 mice, treated with R848 or not, received $15 \times 10^{6} \mathrm{~B} 6 \mathrm{CD}^{+}$cells labeled with CFSE from B6 mice not treated (NT) or treated with R848 $48 \mathrm{~h}$ before cell transfer. After 6 days, anti$\mathrm{H}-2 \mathrm{D}^{\mathrm{d}},-\mathrm{H}-2 \mathrm{D}^{\mathrm{b}}$ and $-\mathrm{TCR} \beta$ antibodies were used to analyze the proliferation level of B6 T cells in host spleen by flow cytometry. (B-E) 14 days after total B6 spleen cell transfer, spleen cell subsets were enumerated by FACS, using anti-H2D d, -H2D ${ }^{b}$, -CD4, -CD8, -CD44, -CD62 L and -CD69 antibodies. (B) Plots show absolute numbers of CD4 and CD8 T cells. (C) CD44, CD62L and (D) CD69 expression by T cells is represented with density plots or histograms for percentages and plots for absolute numbers. (E) $\mathrm{H}-2 \mathrm{D}^{\mathrm{d}}, \mathrm{H}-2 \mathrm{D}^{\mathrm{b}}$, LIVE/DEAD ${ }^{\oplus}, \mathrm{CD} 4, \mathrm{TCR} \beta$ and Foxp3 staining was used to determine by flow cytometry the percentage (left) and absolute number (right) of Treg in host spleen 14 days after induction of GvHD. Data are from two to three experiments in all panels $(* P<0.05, * * P<0.01, * * * P<0.001$ by the Kruskal-Wallis test with Dunn multiple comparison test or Mann-Whitney unpaired $t$-test). 
A

B6 Foxp3+ CD4 T cells (Day+14)

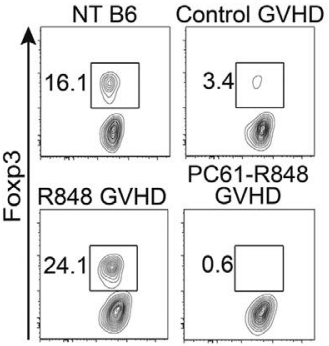

B

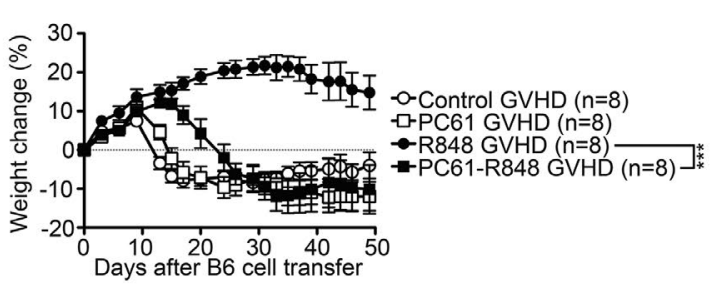

D
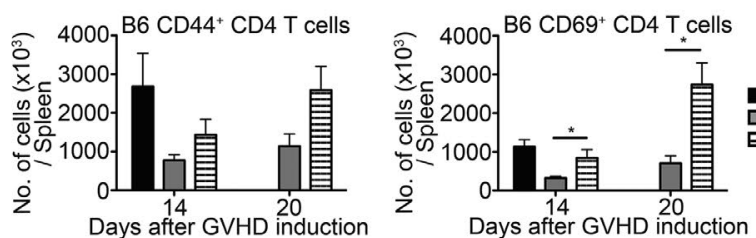

C

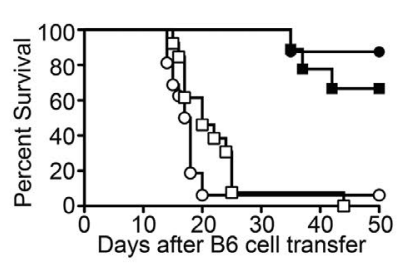

B6 FoxP3 $3^{+} \mathrm{CD} 4 \mathrm{~T}$ cells

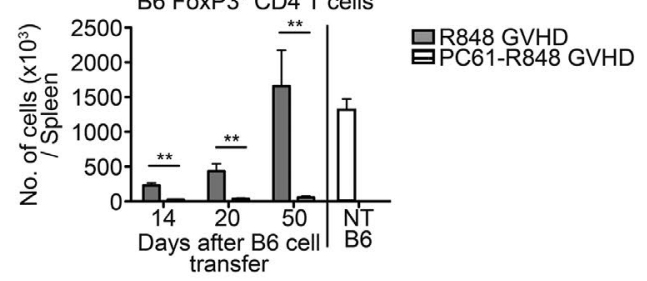

$\mathbf{E}$
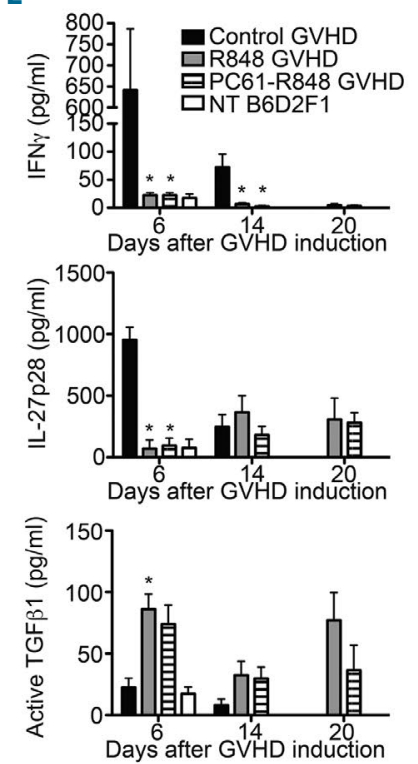

Figure 5. Foxp $3^{+}$regulatory T cells are involved in graft-versus-host disease prevention by R848. Treg were depleted with PC61 antibody in donor and recipient mice 4 days before R848 treatment and 1 day after B6 cell transfer in the non-conditioned GvHD model. (A) After 14, 20 and 50 days of B6 cell implantation, H-2D ${ }^{d}$, H$2 D^{b}$, LIVE/DEAD ${ }^{\circledast}, C D 4, T C R \beta$ and Foxp3 staining was used to evaluate Treg populations by flow cytometry. Mice were monitored for (B) weight loss and (C) mortality. (D) Anti-CD44 and -CD69 antibodies were used to analyze T-cell activation after 14 and 20 days. (E) IFN $\gamma$, IL-27p28 and active TGF $\beta$ - 1 were measured by enzymelinked immunosorbent assay in plasma prepared from mice bled on days 6,14 and 20 . Data are from two to three experiments in all panels ( ${ }^{*}<0.05$, $* * ~ P<0.01$, $* * * P<0.001$ by the Kruskal-Wallis test with Dunn multiple comparison test, Mann-Whitney unpaired t-test and ANOVA-Bonferroni post-test).

mice, half of the initial Treg population recovered 14 days after GvHD induction. In contrast, in R848-treated GvHD mice, B6D2F1 Treg numbers almost doubled compared to normal B6D2F1 mice and increased four times versus PC61R848 ncGVHD mice and their levels remained unchanged up to day 50 after transplantation (Online Supplementary Figure $S 2 A, B)$.

PC61 treatment of the R848 GvHD mice resulted in weight loss starting from day 17, a few days later than in control GvHD mice. The percentage weight loss was finally the same in both groups, suggesting a significant contribution of Treg in the prevention of ncGVHD morbidity by R848 (Figure 5B). However, PC61 treatment only partially decreased the survival of R848-treated mice $(70 \%$ versus $90 \%$ ) (Figure $5 \mathrm{C}$ ). This trend was observed in two additional experiments.

In order to test whether Treg depletion affected the level of donor T-cell activation, we evaluated CD44 and CD69 expression levels 14 and 20 days after ncGVHD induction. When Treg were depleted in R848-treated mice, CD44 ${ }^{+}$ and $\mathrm{CD}_{69}{ }^{+} \mathrm{B} 6 \mathrm{CD} 4$ and $\mathrm{CD} 8 \mathrm{~T}$ cells were significantly increased and CD69 levels even exceeded those of the control ncGVHD group. Compared to day 14 levels, the B6 $\mathrm{CD} 69^{+} \mathrm{T}$-cell population tripled at day 20 , indicating that an absence of Treg increased expansion of memory and activated donor $\mathrm{T}$ cells (Figure 5D). However, Treg depletion by PC61 did not seem to influence early cytokine production since no significant differences in IFN $\gamma$, IL-27p28 and active TGF- $\beta 1$ plasma concentrations were observed between R848- and PC61-R848-treated mice (Figure 5E).

Together, the data suggest that Treg from donors and recipients contributed to R848-mediated GvHD prevention. However, despite the depleting treatment, a small population of host Treg remained present, which could explain why $\mathrm{R} 848$ protection was not completely abrogated and resulted in death of only $30 \%$ of PC61-R848-treated mice. As shown previously, R848 GvHD protection correlates with a strong drop in pro-inflammatory cytokines and this was still observed after Treg depletion, which could also explain why the protective effect of R848 was not completely suppressed by Treg depletion. 
A

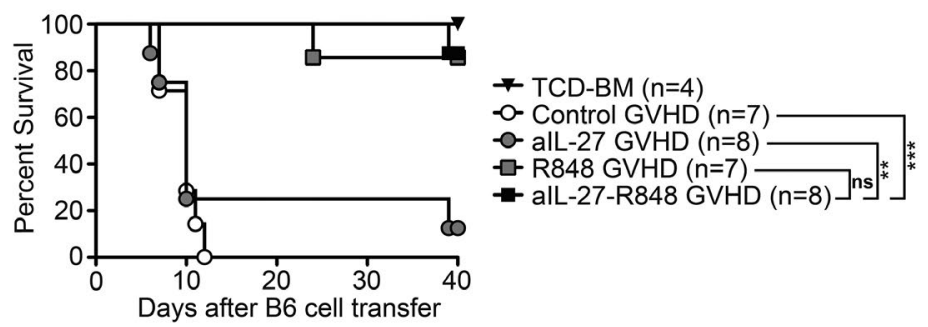

Figure 6. R848 and anti-interleukin27 p28 monoclonal antibody administration to recipient mice prevents acute graft-versus-host disease in irradiated models. (A) BALB/c recipient mice were irradiated with 8 Gy and treated or not with R848 (25 $\mu \mathrm{g} /$ mouse) $48 \mathrm{~h}$ and $0 \mathrm{~h}$ before transplantation of $2 \times 10^{6} \mathrm{~B} 6 \mathrm{CD} 5$ splenocytes and $10^{7} \mathrm{~B} 6 \mathrm{~T}$-cell depleted bone marrow cells (TCD-BM). In addition, both recipient groups were treated or not (NT) with $0.5 \mathrm{mg}$ antiIL-27 (alL-27) on days 0 and 6. Mice were monitored for survival. (B) Six days after B6-cell transfer, IFN $\gamma$ and IL-27p28 were measured by enzymelinked immunosorbent assay in plasma from irradiated-GvHD BALB/c mice. (C) B6D2F1 recipient mice were irradiated with 5 Gy and treated or not with R848 ( $25 \mu \mathrm{g} /$ mouse) 48 and $24 \mathrm{~h}$ before transplantation of $40 \times 10^{6}$ splenocytes and $10^{7}$ TCD-BM cells from B6 mice similarly treated with R848 or not. In addition, both recipient groups were treated or not with alL-27 $(0.5 \mathrm{mg})$ on days 0 and 6 . Mice were monitored for survival. Data are representative of two to three experiments. $(* P<0.05$, $* * P<0.01, * * * P<0.001$ by the log

C

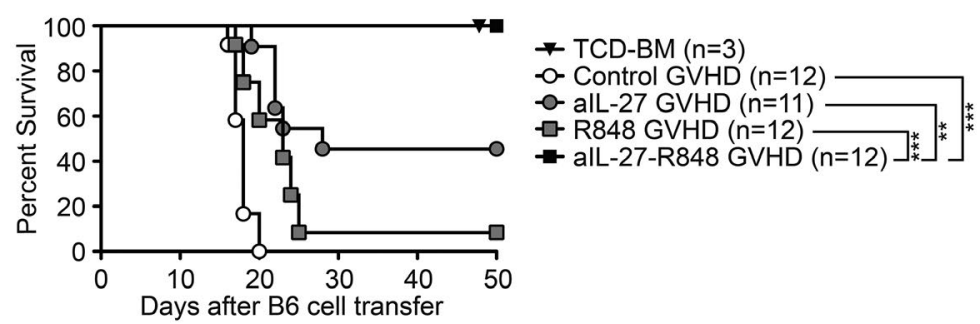

rank test and Kruskal-Wallis test with Dunn multiple comparison test).

R848 cooperates with anti-interleukin-27p28 monoclonal antibody in regulatory T-cell upregulation and graft-versus-host disease prevention in conditioned models

B6 spleen cell transfer into ncB6D2F1 recipients is an optimal strategy for dissecting the mechanisms involved in immune-mediated hematopoietic cell destruction and can be used as a model of induced bone marrow failure ${ }^{23}$ but does not fully replicate allogeneic HCT. To test R848 in full allogeneic HCT, BALB/c mice were injected with R848 $24 \mathrm{~h}$ before irradiation (8 Gy) and immediately after B6 spleen and bone marrow cell transfer (B6 $\rightarrow 8 G y-B A L B / c)$. All untreated mice rapidly developed acute $\mathrm{GvHD}$ and started to die from day 7 whereas $90 \%$ of the mice injected with R848 survived more than 40 days (Figure 6A).

However, R848 did not completely prevent the GvHD reaction since IL-27p28 and IFN $\gamma$ were still upregulated in R848-protected mice (Figure 6B). This incomplete suppression of a GvHD reaction was even more striking in sublethally irradiated (5 Gy) B6D2F1 recipients of B6 spleen cells, in which R848 pre-treatment of host and donor before transplantation, as in the experiments described above in non-conditioned mice, solely delayed disease and no longer increased survival significantly (Figure 6C), contrary to the total protection seen in non-irradiated recipients. This also correlated with the persistence of pro-inflammatory cytokines IL-27p28 and IFN $\gamma$, which R848 treatment failed to decrease (data not shown). As IL-27, which has been shown to contribute to GvHD pathology, ${ }^{10,11}$ was still present in the irradiated models, we tested the combination of R848 and anti-IL-27 and observed that this resulted in $100 \%$ survival of the 5 Gy-irradiated B6D2F1 recipients (Figure 6C).

The anti-IL-27-R848 combination also operated in B6 $\rightarrow 8 \mathrm{~Gy}-\mathrm{BALB} / \mathrm{c}$ GvHD as it significantly decreased the concentration of plasma IFN $\gamma$, which was not the case when either agent was used separately (Figure 6B). However, it did not prevent T-cell engraftment since we observed the same numbers of CD4 and CD8 T cells (Figure 7A) and total B6 donor cell implantation (Figure 7B). Already after 6 days, the number of B6 CD4 T cells recovered from the BALB/c spleen was equivalent to the total number injected and for CD8 $\mathrm{T}$ cells the number of cells had increased \pm 10 -fold. These numbers were not modified by R848, anti-IL-27 or the anti-IL-27-R848 combination (Figure 7A). Similarly, upregulation of the memory marker CD44 and the activation marker CD69 in B6 CD4 and CD8 T cells recovered 6 days after transplantation were not modified by R848. The only difference was observed for the CD62L naive cell marker that was completely lost in B6 CD4 and CD8 T cells recovered from control GvHD mice but remained significantly higher in the group treated with the anti-IL-27-R848 combination (Online Supplementary Figure S3A).

As we previously showed that Treg contribute to the R848 protection in B6 $\rightarrow$ ncB6D2F1 GvHD, Treg popula- 
A
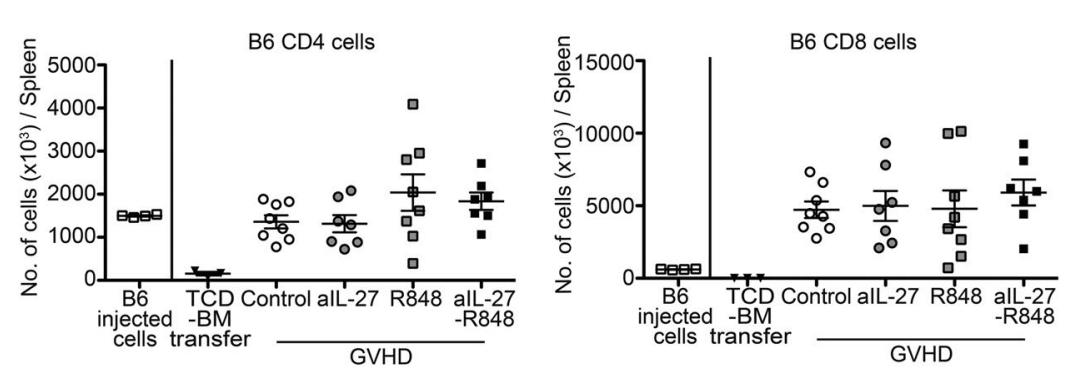

B

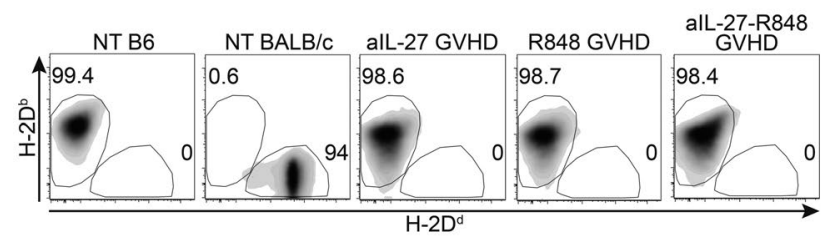

C

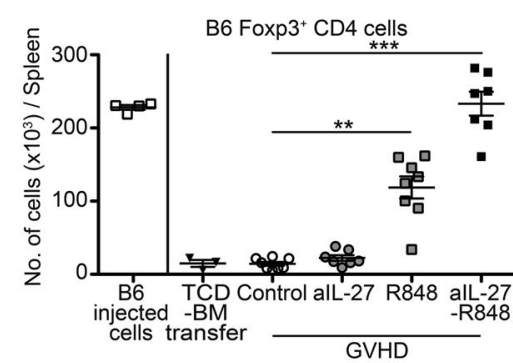

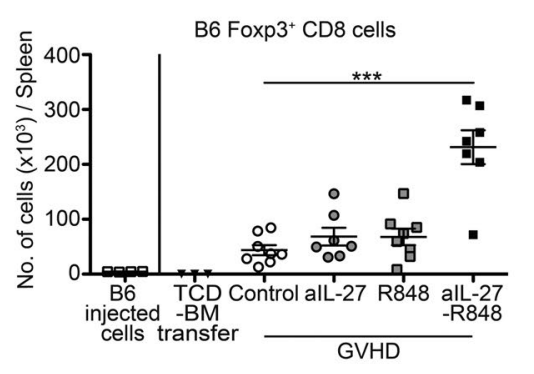

D
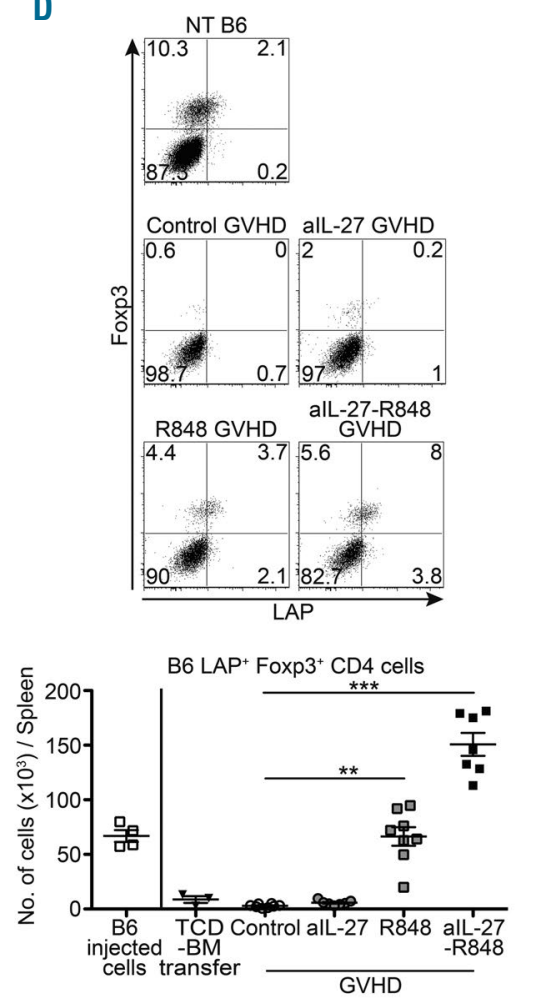

Figure 7. The combination of anti-interleukin-27p28 monoclonal antibody and R848 induces strong regulatory T-cell activation in acute graft-versus-host disease in irradiated recipients. BALB/c recipient mice were irradiated with 8 Gy and treated or not with R848 (25 $\mu \mathrm{g} / \mathrm{mouse}) 48$ and $0 \mathrm{~h}$ before transplantation of $2 \times 10^{6}$ $\mathrm{CD}^{+}$splenocytes from B6 mice. In addition, recipients were treated or not with anti-interleukin-27p28 (alL-27) on days 0 and 6 . After (A) 6 and (B) 40 days of GvHD induction, spleen cells were recovered and stained with anti-H-2D ${ }^{d},-H-2 D^{b},-C D 4$ and $-C D 8$ for FACS spleen cell subset analysis. (C-D) H-2D ${ }^{d}$, H-2D ${ }^{b}$, LIVE/DEAD ${ }^{\oplus}, C D 4$, CD8, LAP and Foxp3 staining was added on 6 -day-GvHD spleen cells to evaluate Treg populations. Data are from two to three experiments $(* * P<0.01, * * * P<0.001$ by the Kruskal-Wallis test with Dunn multiple comparison test).

tions were also analyzed 6 days after $\mathrm{B} 6 \rightarrow 8 \mathrm{~Gy}-\mathrm{BALB} / \mathrm{c}$ GvHD induction. The numbers of Foxp3 ${ }^{+} \mathrm{CD} 4 \mathrm{~T}$ cells were significantly higher in the R848-treated group than in the control group and adding anti-IL-27 to the R848 treatment further increased the Treg population 2-fold (Figure 7C). Sixty-five percent of these Foxp3 ${ }^{+}$CD4 cells were positive for latent TGF- $\beta 1$-associated protein (LAP), attesting their state of activation (Figure 7D). The stimulating effect of the anti-IL-27-R848 combination on Foxp3 expression was even more striking for CD8 Foxp3 ${ }^{+} \mathrm{T}$ cells, which were barely detectable in the donor B6 spleen but reached levels equivalent to their $\mathrm{CD} 4$ counterparts in the anti-IL-27-R848 group. This was not seen in mice treated with either R848 or anti-IL-27 (Figure 7C). Interestingly, following anti-IL-27 treatment, B6 Foxp3 ${ }^{+}$ CD4 T cells increased 3 -fold more than in the control GvHD group and $75 \%$ of these cells were activated. In contrast, R848 administration did not significantly amplify these cells, which correlated with the failure of the TLR7 ligand to increase survival in B6 $\rightarrow 5 \mathrm{~Gy}-\mathrm{B} 6 \mathrm{D} 2 \mathrm{~F} 1$ mice. The anti-IL-27-R848 combination induced a strong increase of Foxp3 ${ }^{+} \mathrm{CD} 4 \mathrm{~T}$ cells, which were 5 -fold more numerous than in control GvHD mice and $85 \%$ were $\mathrm{LAP}^{+}$. In this irradiated model, the Foxp3 ${ }^{+} \mathrm{CD} 8$ population, although present, was substantially less abundant (Online Supplementary Figure S3B).
Thus, R848 treatment failed to provide complete protection against conditioned GvHD but full protection was restored when anti-IL-27 was added. The combination was necessary to abrogate IFN $\gamma$ production and to induce maximal Foxp3 ${ }^{+} \mathrm{CD} 4$ and $\mathrm{CD} 8$ cell responses.

\section{Discussion}

Innate pattern recognition receptors, including TLR, are implicated in the control of GvHD. ${ }^{37}$ Most often TLR stimulation aggravates disease, as reported for TLR4 ${ }^{38}$ and TLR9, ${ }^{39}$ but the consequences may differ depending on the time of TLR stimulation with respect to allogeneic HCT as observed for the TLR7/8 agonist 3M-001. 40,41

The present study demonstrates the prevention of murine GvHD by the TLR7 ligand resiquimod/R848 and further improvement of protection by inhibition of IL-27.10,11 Our results indicate that $\mathrm{R} 848$ administration to recipients $48 \mathrm{~h}$ before and at the time of allogeneic HCT promoted survival in lethally irradiated recipients of fully allogeneic hematopoietic cells and in the lethal form of GvHD induced in ncB6D2F1 recipients of B6 parental spleen cells. In this model, R848 inhibited IFN $\gamma$, IL-27 and TNF $\alpha$ production while upregulating TGF- $\beta 1$, thus altering the cytokine balance. However, this suppression of Th1 cytokine produc- 
tion was not observed in mice with conditioned GvHD which were also protected by R848, suggesting that inhibition of IFN $\gamma$, IL-27 and TNFa was not the only underlying mode of action. This conclusion was indirectly confirmed in the sublethally irradiated $\mathrm{B} 6 \rightarrow \mathrm{B} 6 \mathrm{D} 2 \mathrm{~F} 1$ model in which R848 was not protective on its own but still enhanced protection by anti-IL-27. Together, these results indicate that the protective activity of R848 involves but is not limited to IL-27 inhibition as its effect could still be improved by antibody-mediated IL-27 inhibition.

In the $\mathrm{B} 6 \rightarrow \mathrm{ncB} 6 \mathrm{D} 2 \mathrm{~F} 1 \mathrm{GvHD}$ model, complete protection required treatment of both the donor and recipient. As the contribution of F1 recipients to GvHD is limited to antigen presentation, these results suggest that R848 impaired both $\mathrm{APC}$ and T-cell responders. Analyses performed just before GvHD induction confirmed this hypothesis since DC antigen presentation and T-cell allo-responsiveness were inhibited in spleen cells collected from R848-treated mice. In agreement with the literature, ${ }^{42}$ we observed that R848 induced a transient loss and functional inhibition of splenic cDC (both $\mathrm{CD} 11 b^{+}$and $\mathrm{CD} 8 \alpha^{+}$), the main cells able to induce allogeneic responses in vitro and that are known to play an important role in GvHD induction in vivo. ${ }^{43,44}$ This drop in splenic DC was very transient and antigen presentation returned to normal after 7 days (unpublished observation), suggesting that a short inactivation of host DC is sufficient to alter the initiation of GvHD. R848 induced a similar inhibition of the capacity of $\mathrm{T}$ cells to respond to allogeneic in vitro stimulation. Type I interferons seem to be critical in the suppression of DC and T-cell allo-responsiveness by R848 as both remained unaltered in R848-treated IFNAR-1 mice. This observation is in line with reported inhibition of DC and CD4 T cells by type I interferons. ${ }^{24}$

Importantly, the inhibition of T-cell allo-responsiveness by R848 in vivo treatment, demonstrated by ex vivo mixed lymphocyte cultures, did not prevent their implantation as chimerism was maintained for months. Moreover, the implanted $\mathrm{T}$ cells completely lost naive T-cell marker CD62L and showed only partial inhibition of CD44 and CD69 memory and activation marker upregulation. This implies the existence of other regulatory mechanisms permitting the persistence of donor $\mathrm{T}$ cells in the host with reduced GvHD manifestations. A likely explanation was the effect of R848 on donor and recipient Foxp3 ${ }^{+}$Treg. The number of these cells dropped dramatically during GvHD but not in R848-treated mice in which their numbers even increased compared to basal control levels. This was particularly striking for Foxp3 ${ }^{+}$CD8 T cells. Moreover, the presence of LAP on their surface demonstrated that these cells were in an activated state. These results are in agreement with the upregulation of Treg by R848 reported in an asthma model ${ }^{45}$ Given the implication of Treg in the control of $\mathrm{GvHD},{ }^{19,20}$ this Treg stimulation probably contributed to the protective effect of R848. This conclusion was substantiated by the observation that depletion of Treg by anti-CD25 antibody treatment restored morbidity to levels equivalent to those of control GvHD mice although survival was only partly impaired. The importance of Treg upregulation for GvHD prevention by R848 was further demonstrated in the B6 $\rightarrow$ 5Gy-B6D2F1 model in which R848 treatment failed to induce a robust Treg response which correlated with poor survival. Interestingly, adding anti-IL-27p28 monoclonal antibody to R848 restored the Treg response and resulted in complete protection. These results are in line with reported
GvHD impairment by in vitro R848 stimulation of Treg ${ }^{46}$ and reveal the R848-anti-IL-27 combination as a new option for maximal Treg upregulation and prevention of GvHD without inhibiting donor cell implantation.

R848 upregulated plasma levels of active TGF- $\beta 1$ during GvHD, which probably contributed to the observed increase in Treg and to the inhibition of allogeneic T-cell responsiveness that characterized $\mathrm{T}$ cells recovered from R848-treated mice. These results are in agreement with the reported severity of murine GvHD induced by donors lacking SMAD ${ }^{35}$ as well as the predictive impact of TGF- $\beta$ expression in human allogeneic HCT donors on GvHD occurrence. ${ }^{47}$ The beneficial effect of high TGF- $\beta 1$ levels could be related not only to Foxp3 ${ }^{+}$Treg cell expansion but also to the capacity of TGF- $\beta$ to inhibit cytotoxic T-cell development. ${ }^{48}$

The complete and long-lasting donor Treg elimination by anti-CD25 antibody only partly suppressed GvHD prevention by R848. This phenomenon could be explained by the presence of a small host Treg population, which recovered after 14 days and remained stable during the course of the GvHD. This partial suppression of R848 protection could also be explained by the other suppressive mechanisms induced by the drug, such as type I interferon-mediated inhibition of DC and T cells and the downregulation of Th1 cytokines mentioned earlier.

In summary, our results demonstrate that, in the context of allogeneic HCT, R848 alters both alloantigen presentation by $\mathrm{CDC}$ and Th1-cell responsiveness in a process dependent on type I interferons and correlating with increased TGF- $\beta 1$ as well as Treg expansion and diminished IFN $\gamma$, TNF $\alpha$ and IL-27 production. When not sufficient on its own, R848 protection can be further enhanced by antiIL-27p28 monoclonal antibody leading to maximal expansion of Foxp3 ${ }^{+}$Treg cells. A remarkable feature of this novel GvHD preventive procedure is that it needs to be applied only just before and at the time of allogeneic HCT and results in permanent coexistence of the host and allogeneic $T$ cells with a significant reduction in GvHD symptoms.

Transposing these data to human conditions raises a number of issues. One is that R848 activation could be more complex in humans as it activates both TLR7 and TLR8, the latter being inactive in mice. Should this raise problems one could, however, use other agents that activate only TLR7 in humans, such as CL264, a 9-benzyl-8 hydroxyadenine derivative. Another issue is the expression of TLR7 by human not murine CD4 T cells. ${ }^{49,50}$ This could in fact further improve the efficacy of TLR7-based prevention of GvHD since engaging TLR7 in human CD4 T cells induces a NFATc2-dependent anergy. ${ }^{50}$

\section{Acknowledgments}

MG is a FNRS-FRIA PhD Fellow at the Universite Catholique de Louvain. RGM is a Haas-Teichen Fellow of the de Duve Institute. JPC is FNRS research director. The technical help of Pamela Cheou and Emilie Hendrickx and the editorial assistance of Suzanne Depelchin are gratefully acknowledged.

\section{Funding}

This work was supported by the Belgian National Fund for Scientific Research (FNRS), the "Fondation Contre le Cancer" (FCC)(2010-165), the Joseph Maisin Fund, the Interuniversity Attraction Pole of the Belgian Federal Science Policy, and Actions de Recherche Concertée from Fédération Wallonie-Bruxelles. 


\section{References}

1. Appelbaum FR. Hematopoietic cell transplantation from unrelated donors for treatment of patients with acute myeloid leukemia in first complete remission. Best Pract Res Clin Haematol. 2007:20(1):67-75.

2. Mahmoud HK, Elhaddad AM, Fahmy OA, et al. Allogeneic hematopoietic stem cell transplantation for non-malignant hematological disorders. J Adv Res. 2015;6(3):449458.

3. Dvorak CC, Cowan MJ. Hematopoietic stem cell transplantation for primary immunodeficiency disease. Bone Marrow Transplant. 2008;41(2):119-126.

4. Ferrara JL, Levine JE, Reddy P, Holler E. Graft-versus-host disease. Lancet. 2009:373(9674):1550-1561.

5. Choi SW, Reddy P. Current and emerging strategies for the prevention of graft-versushost disease. Nat Rev Clin Oncol. 2014;11(9):536-547.

6. Markey KA, MacDonald KP, Hill GR. The biology of graft-versus-host disease: experimental systems instructing clinical practice. Blood. 2014;124(3):354-362.

7. Couriel DR, Saliba R, de Lima M, et al. A phase III study of infliximab and corticosteroids for the initial treatment of acute graft-versus-host disease. Biol Blood Marrow Transplant. 2009;15(12):1555-1562.

8. Chen X, Das R, Komorowski R, et al. Blockade of interleukin-6 signaling augments regulatory $\mathrm{T}$-cell reconstitution and attenuates the severity of graft-versus-host disease. Blood. 2009:114(4):891-900.

9. Das R, Chen X, Komorowski R, Hessner MJ, Drobyski WR. Interleukin-23 secretion by donor antigen-presenting cells is critical for organ-specific pathology in graft-versushost disease. Blood. 2009;113(10):23522362.

10. Marillier RG, Uyttenhove C, Goriely S, Marbaix E, Van Snick J. IL-27p28 is essential for parent-to-F1 acute graft-versus-host disease. Eur J Immunol. 2014;44(7):2064-2073.

11. Belle L, Agle K, Zhou V, et al. Blockade of interleukin 27 signaling reduces GVHD in mice by augmenting Treg reconstitution and stabilizing FOXP3 expression. Blood. 2016;128(16):2068-2082.

12. Yoshida H, Hunter CA. The immunobiology of interleukin-27. Annu Rev Immunol. 2015;33:417-443

13. Pflanz S, Timans JC, Cheung J, et al. IL-27, a heterodimeric cytokine composed of EBI3 and $\mathrm{p} 28$ protein, induces proliferation of naive $\mathrm{CD} 4(+) \mathrm{T}$ cells. Immunity. 2002;16(6):779-790.

14. Yoshida H, Nakaya M, Miyazaki Y Interleukin 27: a double-edged sword for offense and defense. J Leukoc Biol. 2009;86 (6):1295-1303

15. Dibra D, Cutrera JJ, Li S. Coordination between TLR9 signaling in macrophages and CD3 signaling in T cells induces robust expression of IL-30. J Immunol. 2012;188 (8):3709-3715

16. Pflanz S, Hibbert L, Mattson J, et al. WSX-1 and glycoprotein 130 constitute a signaltransducing receptor for IL-27. J Immunol. 2004:172(4):2225-2231

17. Villarino AV, Larkin J, 3rd, Saris CJ, et al. Positive and negative regulation of the IL-27 receptor during lymphoid cell activation. J Immunol. 2005;174(12):7684-7691.

18. Kastelein RA, Hunter CA, Cua DJ. Discovery and biology of IL-23 and IL-27: related but functionally distinct regulators of inflammation. Annu Rev Immunol.
2007;25:221-242

19. Cohen JL, Trenado A, Vasey D, Klatzmann D, Salomon BL. CD4(+)CD25(+) mmunoregulatory $T$ cells: new therapeutics for graft-versus-host disease. J Exp Med. 2002;196(3):401-406

20. Hoffmann P, Ermann J, Edinger M, Fathman CG, Strober S. Donor-type CD4(+)CD25(+) regulatory $\mathrm{T}$ cells suppress lethal acute graftversus-host disease after allogeneic bone marrow transplantation. J Exp Med. 2002;196(3):389-399

21. Taylor PA, Lees CJ, Blazar BR. The infusion of ex vivo activated and expanded CD4(+)CD25(+) immune regulatory cells inhibits graft-versus-host disease lethality. Blood. 2002;99(10):3493-3499.

22. Gaignage M, Marillier RG, Uyttenhove C, et al. Mouse nidovirus LDV infection alleviates graft versus host disease and induces type I IFN-dependent inhibition of dendritic cells and allo-responsive T cells. Immun Inflamm Dis. 2017;5(2):200-213.

23. Bloom ML, Wolk AG, Simon-Stoos KL, Bard JS, Chen J, Young NS. A mouse model of lymphocyte infusion-induced bone marrow failure. Exp Hematol. 2004;32(12):11631172.

24. Robb RJ, Kreijveld E, Kuns RD, et al. Type IIFNs control GVHD and GVL responses after transplantation. Blood. 2011;118(12): 3399-3409.

25. Ammann CG, Messer RJ, Peterson KE, Hasenkrug KJ. Lactate dehydrogenase-elevating virus induces systemic lymphocyte activation via TLR7-dependent IFNalpha responses by plasmacytoid dendritic cells. PLoS One. 2009;4(7):e6105.

26. Hemmi H, Kaisho T, Takeuchi O, et al. Small anti-viral compounds activate immune cells via the TLR7 MyD88-dependent signaling pathway. Nat Immunol. 2002;3(2):196-200

27. Miller RL, Meng TC, Tomai MA. The antiviral activity of Toll-like receptor 7 and $7 / 8$ agonists. Drug News Perspect. 2008;21(2): 69-87.

28. Holbrook BC, Kim JR, Blevins LK, et al. A Novel R848-conjugated inactivated influenza virus vaccine is efficacious and safe in a neonate nonhuman primate model. J Immunol. 2016;15(2):555-564.

29. Wagner TL, Ahonen CL, Couture AM, et al. Modulation of TH1 and TH2 cytokine production with the immune response modifiers, R-848 and imiquimod. Cell Immunol. 1999;191(1):10-19.

30. Baenziger S, Heikenwalder M, Johansen P, et al. Triggering TLR7 in mice induces immune activation and lymphoid system disruption, resembling HIV-mediated pathology. Blood. 2009;113(2):377-388

31. Muller U, Steinhoff U, Reis LF, et al. Functional role of type I and type II interferons in antiviral defense. Science. 1994;264(5167):1918-1921.

32. Uyttenhove C, Marillier RG, TacchiniCottier F, et al. Amine-reactive OVA multimers for auto-vaccination against cytokines and other mediators: perspectives illustrated for GCP-2 in L. major infection. J Leukoc Biol. 2011;89(6):1001-1007

33. Lowenthal JW, Corthesy P, Tougne C, Lees R, MacDonald HR, Nabholz M. High and low affinity IL 2 receptors: analysis by IL 2 dissociation rate and reactivity with monoclonal anti-receptor antibody PC61. J Immunol. 1985;135(6):3988-3994

34. Hattori $\mathrm{K}$, Hirano $\mathrm{T}$, Miyajima $\mathrm{H}$, et al. Differential effects of anti-Fas ligand and anti-tumor necrosis factor alpha antibodies on acute graft-versus-host disease pathologies. Blood. 1998;91(11):4051-4055

35. Giroux M, Delisle JS, Gauthier SD, et al. SMAD3 prevents graft-versus-host disease by restraining Th1 differentiation and granulocyte-mediated tissue damage. Blood. 2011;117(5):1734-1744

36. Hattori $\mathrm{H}$, Matsuzaki A, Suminoe A, et al Polymorphisms of transforming growth factor-betal and transforming growth factorbeta1 type II receptor genes are associated with acute graft-versus-host disease in children with HLA-matched sibling bone marrow transplantation. Bone Marrow Transplant. 2002;30(10):665-671.

37. Penack O, Holler E, van den Brink MR Graft-versus-host disease: regulation by microbe-associated molecules and innate immune receptors. Blood. 2010;115(10): 1865-1872

38. Cooke KR, Gerbitz A, Crawford JM, et al LPS antagonism reduces graft-versus-host disease and preserves graft-versus-leukemia activity after experimental bone marrow transplantation. J Clin Invest. 2001;107(12): 1581-1589.

39. Calcaterra C, Sfondrini L, Rossini A, et al. Critical role of TLR9 in acute graft-versushost disease. J Immunol. 2008:181(9):61326139

40. Taylor PA, Ehrhardt MJ, Lees CJ, et al. TLR gonists regulate alloresponses and uncover a critical role for donor APCs in allogeneic bone marrow rejection. Blood. 2008;112(8): 3508-3516.

41. Jasperson LK, Bucher C, PanoskaltsisMortari A, et al. Indoleamine 2,3-dioxygenase is a critical regulator of acute graft-versus-host disease lethality. Blood. 2008;111(6):3257-3265

42. Assier E, Marin-Esteban V, Haziot A, Maggi E, Charron D, Mooney N. TLR7/8 agonists impair monocyte-derived dendritic cell diferentiation and maturation. I Leukoc Biol. 2007;81(1):221-228.

43. Shlomchik WD, Couzens MS, Tang CB, et al. Prevention of graft versus host disease by inactivation of host antigen-presenting cells. Science. 1999;285(5426):412-415.

44. Markey KA, Banovic T, Kuns RD, et al. Conventional dendritic cells are the critical donor APC presenting alloantigen after experimental bone marrow transplantation. Blood. 2009;113(22):5644-5649.

45. Van LP, Bardel E, Gregoire S, et al. Treatment with the TLR7 agonist R848 induces regulatory T-cell-mediated suppression of established asthma symptoms. Eur J Immunol. 2011:41(7):1992-1999.

46. Zogas N, Karponi G, Iordanidis F, et al. The ex vivo toll-like receptor 7 tolerance induction in donor lymphocytes prevents murine acute graft-versus-host disease. Cytotherapy. 2018;20(1):149-164.

47. Baron C, Somogyi R, Greller LD, et al Prediction of graft-versus-host disease in humans by donor gene-expression profiling. PLoS Med. 2007;4(1):e23.

48. Ranges GE, Figari IS, Espevik T, Palladino MA Jr. Inhibition of cytotoxic T cell development by transforming growth factor beta and reversal by recombinant tumor necrosis factor alpha. J Exp Med. 1987;166(4):991998.

49. Rahman AH, Taylor DK, Turka LA. The contribution of direct TLR signaling to T cell responses. Immunol Res. 2009:45(1):25-36.

50. Dominguez-Villar M, Gautron AS, de Marcken M, Keller MJ, Hafler DA. TLR7 induces anergy in human CD4(+) T cells. Nat Immunol. 2015;16(1):118-128. 